\title{
Climate panel to seize political hot potatoes
}

Quirin Schiermeier, Munich

The politically sensitive issues of carbon sequestration and regional climate forecasts are to form part of the fourth assessment report by the Intergovernmental Panel on Climate Change (IPCC).

The assessment, due in 2007, was discussed by some 300 IPCC members in Paris on 19-21 February. Sequestration was chosen as the subject for a special report, separate from the main assessment. After the meeting, Rajendra Pachauri, director of the Tata Energy Research Institute in New Delhi and chair of the IPCC, confirmed that more detailed regional models of the impact of climate change would be considered by the assessment's authors.

Previous regional projections have generated controversy. A 2000 report from the US Global Change Research Program described the possible regional effects of climate change in the United States, but the results of this and other similar studies were deemed too unreliable by the Bush administration to be included in its strategy for climate-change research, released last November (see Nature 420, 110; 2002).

"I am aware that there is an opportunity for much political debate when you start to predict the impact of climate change on specific regions," said Pachauri. "But if you want

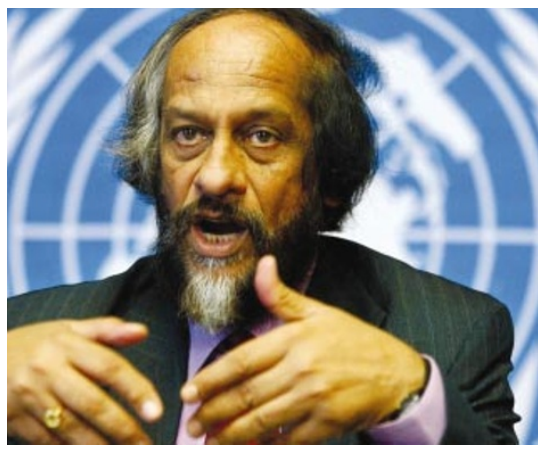

Rajendra Pachauri: information is vital for action.

action you must provide this information."

Carbon-sequestration schemes, such as using empty oilfields to store the carbon dioxide from power plants, also provoke strong reactions. Environmental groups accuse advocates of the idea of damaging attempts to reduce emissions of greenhouse gases.

But the panel's fourth assessment will come too late to provide scientific input into negotiations on greenhouse-gas emission targets for 2013 onwards, the second phase of the Kyoto Protocol. Talks on these targets begin in 2005. "We will have to come up with some means to update negotiators with the latest scientific information," said Pachauri. One possibility, he said, would be for some panel members to hold workshops to provide tentative directions for the negotiating parties.

The run-up to the Paris meeting was overshadowed by criticism of a previous IPCC special report on emission scenarios, which explored how changes in global economic and social conditions could affect emissions. In several papers over the past year, economists Ian Castles of the Australian National University in Canberra and David Henderson of Westminster Business School in London argued that the scenarios were "technically unsound" because of false assumptions on likely economic growth in developing countries.

Pachauri and others at the meeting agreed that the projections may need minor changes, but denied that they are flawed. "The emissions scenarios covered a very broad range," said Thomas Stocker, a climate modeller at the University of Bern in Switzerland, and a lead author on the third assessment report. "It is extremely unlikely that they do not include the actual development of emissions."

Details of the next assessment will be approved at an IPCC meeting in October. The IPCC will then appoint about 2,000 authors and reviewers from around the world, who could then begin work next year. Pachauri says he is keen to involve more young authors.

\section{Experts cast doubt on Britain's green energy ambitions}

\section{Natasha McDowell, London}

Plans for a new UK Energy Research Centre and a dedicated facility to test ocean-wave energy are the highlights of the research component of Britain's energy strategy, published on 24 February. But experts have questioned whether these and other proposals have the political and financial backing to meet the government's goal, announced in the strategy, of cutting carbon dioxide emissions by $60 \%$ by 2050 .

$\Xi$ The plans, unveiled in a government

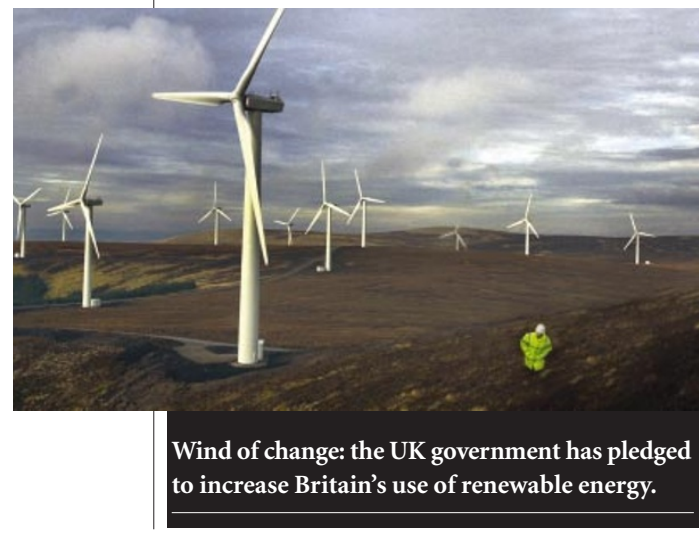

white paper on Britain's energy needs, recognize energy-efficiency measures and renewable energy sources as the principal means of cutting emissions. The paper sets a goal of having $20 \%$ of Britain's energy derived from renewable sources by 2020 and includes no plans for new nuclear power stations.

"It made a lot of the right noises, but did not identify any new policies committing the government to these goals," says Paul Ekins, a professor of sustainable development at the University of Westminster, London.

Such scepticism is derived in part from a lack of concrete measures to help promote renewable sources. One exception is the publicly funded wave-energy test centre the first in Europe - that will open this year off the coast of the Orkney Islands, Scotland. Costing around $\mathfrak{E 5 . 5}$ million (US\$8.7 million), it will assess full-scale wave-energy machines. "The site is vital for the commercial development of wave energy," says Max Carcas of Ocean Power Delivery, an Edinburgh-based company that is developing a commercial offshore wave-power device.

Also highlighted in the white paper is a new UK Energy Research Centre, which will be established in the coming year. Details are still being finalized, but the facility is intended to act as the hub of a new National Energy Research Network, bringing together the strands of energy research funded by the government. The funding for the centre is

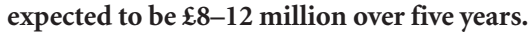

These projects will be complemented by an extra $\mathfrak{E} 60$ million in grants to expand the use of existing renewable technologies, such as wind power. But this will take government spending on such technologies to only $\mathfrak{E} 348$ million over the next four years - a figure that some feel is too small to meet the new emissions goals. Jeremy Leggett, chief executive of Solar Century, a London-based company that sells solar panels, says that the funding is an order of magnitude less than in other European nations such as Germany.

Others say that by rejecting nuclear power and not investing enough in renewable sources, the government has dodged the question of how to move away from using oil and gas. "The white paper shows a lack of courage to make the hard decisions necessary to move this country away from dependence on fossil fuels," argues David Wallace, vicechancellor of Loughborough University and vice-president of the Royal Society. 